\title{
Autosomal dominant polycystic kidney disease type 1 with tuberous sclerosis
}

INSERM

\section{Source}

INSERM. (1999). Orphanet: an online rare disease and orphan drug data base. Autosomal dominant polycystic kidney disease type 1 with tuberous sclerosis. ORPHA:88924

Polycystic kidney disease with tuberous sclerosis (PKD-TSC) is characterised by earlyonset and severe polycystic kidney disease with various manifestations of tuberous sclerosis (multiple ang iomyolipomas, lymphangioleiomyomatosis and periventricular calcifications of the central nervous system). 